\title{
PRECOCIOUS CENTRAL PUBERTY AND SYSTEMIC LUPUS ERYTHEMATOSUS. SIMILAR RISK FACTORS
}

\author{
Marina Ferreira Simões ${ }^{1},{ }^{\star}$, Isabela Tambelli Pires Cardoso ${ }^{1}$, Daniela Gomes Chicre Oliveira ${ }^{1}$, Carlos Eduardo Garcez Teixeira ${ }^{1}$, \\ Simone Appenzeller ${ }^{1}$, Gil Guerra Junior ${ }^{1}$, Lilian Tereza Lavras Costallat ${ }^{1}$
}

1.Universidade Estadual de Campinas, Campinas (SP), Brazil.

*Corresponding author: marina.f.simoes@gmail.com

\section{BACKGROUND}

Puberty represents a complex biological process of sexual development that can be affected by genetic, nutritional, environmental, and socioeconomic factors. Systemic lupus erythematosus (SLE) is an autoimmune disease where the similar triggers are essential for disease-onset in genetic predisposed individuals.

\section{CASE REPORT}

Patient presented at the service at the age of 5 , with a history of breast enlargement, which was painful to the touch. Patient with no history of comorbidities, born at term by vaginal delivery in a hospital environment and normal neuropsychomotor development. On examination, she had breast bud (M2). Hormonal cytology exam showing hypotrophic smear tending to trophic, dosage FSH and LH above reference values. Bone age study compatible with 5 years and 9 months according to the Greulich-Pyle method, skull radiography with intact bone structures, normal sella turcica, absence of calcifications or signs of intracranial hypertension. Abdominal ultrasound with slightly increased uterine volume, with preserved contours and echotexture, presence of endometrial echo measuring $6 \mathrm{~mm}$, ovaries with diffusely distributed cortical follicular cysts. Luteinizing-hormone releasing hormone (LHRH) stimulation test was performed, and then, the diagnosis of central precocious puberty was concluded. She started using $100 \mathrm{mg}$ medroxyprogesterone every 21 days, after which she made daily use of cyproterone, followed by an LHRH analogue. At 8 years of age, she presented M2P3 development, with bone age assessment using the Greulich-Pyle method compatible with 11 years. She stopped using any medications at the age of 9 , with bone age compatible with 9 years and 9 months by the TW2 20 bones method, without progression of secondary sexual characteristics. She presented menarche weighing $36.3 \mathrm{~kg}$ and height of $146 \mathrm{~cm}$. During the follow-up period, she presented headache, fever, asthenia, severe anemia, with peripheral blood smear with significant anisocytosis, microcytosis, macrocytosis and macroplatelets, with diagnosis of red series aplasia. She received pulse therapy with methylprednisolone during a hospital stay, and also received blood transfusion. Subsequently, she presented proteinuria greater than $3 \mathrm{~g}$, positive ANA (1:640 with a speckled nuclear pattern), positive anti-Sm, in addition to lymphopenia and alopecia. Diagnosis of SLE was made, and hydroxychloroquine $5 \mathrm{mg} /$ day, azathioprine $2 \mathrm{mg} /$ day and prednisone were started. She entered remission, had however inferior height as expected.

\section{CONCLUSION}

Environmental effects, including possible roles of stress and early-life exposure to endocrine-disrupting factors, such as estrogenic chemicals, can affect pubertal onset and autoimmune disease, such as SLE.

\section{KEYWORDS}

Systemic lupus erythematosus, Precocious central puberty, Puberty, Lupus, Estrogen. 